\title{
Association of Depression and Life Satisfaction with Low Resilience among Married Women of Karachi, Pakistan
}

\author{
Shireen Shehzad Bhamani1 ${ }^{*}$, Nida Zahid², Iqbal Azam², Nargis Asad ${ }^{3}$, Rozina Karmaliani1,2, \\ Omrana Pasha ${ }^{2}$ \\ ${ }^{1}$ School of Nursing and Midwifery, Aga Khan University, Karachi, Pakistan \\ ${ }^{2}$ Department of Community Health Sciences, Aga Khan University, Karachi, Pakistan \\ ${ }^{3}$ Department of Psychiatry, Aga Khan University, Karachi, Pakistan \\ Email: "shireen.shehzad@aku.edu, bhamanishireen@gmail.com,nida.zahid@aku.edu,iqbal.azam@aku.edu, \\ nargis.asad@aku.edu, rozina.karmaliani@aku.edu, omrana.pasha@aku.edu
}

Received 17 September 2015; accepted 8 November 2015; published 11 November 2015

Copyright (C) 2015 by authors and Scientific Research Publishing Inc.

This work is licensed under the Creative Commons Attribution International License (CC BY). http://creativecommons.org/licenses/by/4.0/

(c) (i) Open Access

\section{Abstract}

Background: The concept of resilience is very crucial in promoting positive psychological wellbeing. However, this construct was never looked among married women of Karachi, Pakistan. Therefore, this study aimed to assess the prevalence and the associated risk factors of resilience in Pakistan. Methods: It was a cross-sectional survey, using the Wagnild Resilience Scale (RS) to assess resilience, Beck Depression Inventory II (BDI-II) for measuring depression and Trait Wellbeing Inventory for determining Life Satisfaction. Systematic sampling was employed to enroll 636 participants of aged 20 to $\mathbf{4 0}$ years living in two urban squatter settlements of Karachi, Pakistan. Prevalence ratio was computed with their $95 \%$ confidence interval. Results: A total of 636 married women participated in the study. The average age of females with low resilience was 29.8 (5.7) whereas the mean age of females with high resilience was 31.1 (5.7). Around $90 \%$ of all the participants could speak in Urdu. The prevalence of low resilience among women was $21.9 \%$. Moreover, the prevalence of depression among low resilience group was $43.9 \%$ whereas the mean life satisfaction score among females with low resilience was lower than females with high resilience. The females who had low resilience were younger and had no formal/informal education as compared to their counterparts. After controlling for other variables, the prevalence of low resilience was 1.78 times more among depressed females as compared to the non-depressed with a $95 \% \mathrm{CI}$ : (1.27 - 2.51). Moreover with every one unit increase in the life satisfaction scores, the prevalence of low resilience decreased $9 \%$. Furthermore, age and informal schooling were also found to be significantly associated with resilience. Conclusion: Depression and life satisfaction are the potential modifiable risk factors for resilience and hence we can improve resilience through interven-

\footnotetext{
*Corresponding author.
}

How to cite this paper: Bhamani, S.S., Zahid, N., Azam, I., Asad, N., Karmaliani, R. and Pasha, O. (2015) Association of Depression and Life Satisfaction with Low Resilience among Married Women of Karachi, Pakistan. Open Journal of Epidemiology, 5, 251-259. http://dx.doi.org/10.4236/ojepi.2015.54029 
tions that may focus on reducing depression and improving satisfaction towards life. Our study also recommends that health care professionals should be educated about these modifiable risk factors to bring about a change in the society and reduce the mental health illness by promoting constructive adaptation.

\section{Keywords}

\section{Resilience, Depression, Life Satisfaction, Married Women, Pakistan}

\section{Introduction}

Resilience is important for a person's mental and physical health. The foundation of resilience is to promote positive psychological well-being, minimize the impact of risk factors, and enhance the protective factors that increase a person's ability to deal with the challenges of life [1]. However responding to life challenges or hardship with resilience doesn't mean that an individual will return to his/her original state after experiencing adversity; in fact this will bring an individual to an equilibrium state [2]. Resilient individuals also exhibit adaptive behavior related to social functioning, self-esteem, and somatic health and are less likely to capitulate to illness [3]. Resilience, as part of an individual's personality traits, builds on and changes over time through constant life experiences with the physical and social environment [4].

Assessing resilience in a vulnerable group is very important because high risk populations who are exposed to psychological issues are able to demonstrate their resilience in a better way. Poverty or low income is one of the possible contributors that cause vulnerability among individuals, families, and communities. Furthermore, better jobs and improved economical sustainability of the community are also the significant markers of resilience [5]. However poverty limits an individual's chance of being educated and employed which leads to weaker social integration, loss of control, depressive symptoms and fatalistic position. Hence, it is true that poverty is a kind of adversity, but not everyone is exposed to this adversity in a similar way. Those who adapt this adversity positively are the ones who are resilient [6].

Resilience protects one against negative mental health issues such as depression, helplessness, fear, anxiety and other negative emotions and therefore it helps to reduce their ill-effects [7]. Studies have shown that during adolescence people had higher resilience [8]. Hence, resilient people revert and recover their balance sooner after hardship and misfortune.

Individuals who are resilient often have a peaceful state of mind. Studies have shown that when hardships and difficulties inflict individuals, resilience has helped them to become stronger. Furthermore, evidence shows that resilience is related to enthusiasm, motivation and speedy recovery from physical or psychological traumatic events [9] [10].

Hence, resilience is a positive adaptation that leads to better health outcomes and it is not a generalized individual trait. Few individuals may demonstrate resilience when hardship inflicts them while others may not [6]. To the best of our knowledge the prevalence of resilience among married women has not been studied in South Asian population. The burden of mental illness particularly depression is increasing in Pakistan especially among females [11] [12]. The budget allocated for the treatment of mental illnesses is also minimal; hence for resource poor countries such as Pakistan, it is imperative to understand the prevailing risk factors for resilience that may help us to identify the preventive strategies to promote constructive adaptation.

Hence the objectives of our study were to determine the prevalence of low and high resilience and to evaluate the association of depression and life satisfaction with low resilience among married women of age 20 to 40 years living in urban squatter settlement of Karachi, Pakistan

\section{Methods}

We conducted a cross-sectional study in two selected urban squatter settlements (Shah Faisal Town and Malir Town) from 10 union councils (UCs) of Karachi, which were clustered based on their low income and one community health center. Although the above two areas had less violence as compared to other UCs but they were selected due to the feasibility. In addition, we had hired and trained the local data collectors from the same 
community so people were quiet comfortable in responding to them. In Shah Faisal Town, we recruited participants from Reta Plot with the total population of 42,968. Whereas in Malir, the participants were enrolled from Kala board whose total population size was 17,997.

This study was the secondary objective of our original project whose primary objective was validation of tools for resilience. Thus the sample size $(n=636)$ for this study was achieved on the basis of our primary objective and the details for the sample size estimation are given elsewhere [13]. A systematic sampling technique was employed as we knew the background of the community structure and the population. The selection of the households was based on the right hand rule. Hence, every $4^{\text {th }}$ house of Malir and $7^{\text {th }}$ house of Shah Faisal was selected. From each house we selected only one female.

We selected our study population from the above communities because we assumed that the married females living there faced a lot of adversities. We included all those females who were currently married, gave an informed consent to participate in the study and were able to converse in Urdu. All those participants were excluded from our study; who had any psychiatric and physical illness or were on any antidepressant drugs.

\section{Data Collection Tools}

We used Wagnild's resilience scale for our study [14]. This tool has been validated in Urdu in our original study [13]. This resilience scale comprised of five core characteristics of resilience that included: purposeful life, perseverance, equanimity, self-reliance and existential loneliness. It comprised of 25 items with 7-point Likert scale to rate the individual's evaluation ranging from 1 (Strongly Disagree) to 7 (Strongly Agree). The dichotomize cut-off of resilience were $<130$ for low resilience and $>130$ for high resilience [2]. We also used a trait well- being inventory to assess life satisfaction. This tool was also validated in Urdu in Lahore, Pakistan. This tool helps to assess the wellbeing of a person. It has seven items that measures cognitive and evaluative aspects of subjective well-being in the present, past and the future. Each item is rated at 6-point Likert-type scale, ranging from 6 ("strongly agree") to 1 ("strongly disagree").

To assess depression we used a 21 item Beck Depression Inventory II (BDI II). Each item consisted of 4 options. Total scores ranged from 0 to 63; higher scores indicated a greater severity of depressive symptoms. This tool has widely been used in Pakistan as it covers the broader behavioural spectrum and is easier to understand. The dichotomize cut-off of depression were a score of $<17$ for no depression and $>17$ for depression.

The demographic profile of the participants was evaluated by a form that consisted of socio-demographic details such as: age, education, language, no of family members, type of marriage and its duration, personal health , reproductive history, working status and possession of own vehicle.

We performed analysis using Statistical Package for the Social Sciences (SPSS), version 19.0. Descriptive statistics were computed for categorical variables by computing their frequencies and the distribution of quantitative variables was computed by their means and standard deviations. Prevalence ratio (PRs) with their 95\% confidence intervals (CIs) was reported using cox regression model.

All ethical considerations were taken into account. Firstly we obtained approval of the study protocol from Aga Khan University (AKU) Ethical Review Committee (ERC). Permission was also gained from the study sites. We reassured complete confidentiality to the study participants. The data was only accessible to the researchers and the responses were reported in group form and no individual case was identified.

\section{Results}

\subsection{Description of the Study Participants}

A total of 636 females were enrolled in the study. The prevalence of low resilience was 139 (21.9\%) and high resilience was 497 (78.1\%). Table 1 presents the socio-demographic status of the study participants. The mean age of the study subjects was lower among females with low resilience as compared to their counterpart. 18.7\% of females with low resilience and $11.9 \%$ of females with high resilience never went to school, while an educational status of higher secondary or above was similar in both the groups. A higher monthly income of $>15,000$ PKR ( $>$ \$142.85) was similar in both the groups.

A higher number of participants with low resilience (18.7\%) had no formal schooling as compared to their counterpart (11.9\%). And similarly about $31.7 \%$ of females with low resilience had no informal schooling as well. The mother tongue of majority of the participants in both the groups was Urdu. Most of the participants 
Table 1. Sociodemographic characteristics of the study subjects.

\begin{tabular}{|c|c|c|}
\hline Socio-demographic factors & $\begin{array}{c}\text { Prevalence of low resilience }(n=139) \\
n(\%)\end{array}$ & $\begin{array}{c}\text { Prevalence of high resilience }(n=497) \\
n(\%)\end{array}$ \\
\hline \multicolumn{3}{|l|}{ Age (years) } \\
\hline $20-24$ & $25(18)$ & 67 (13.5) \\
\hline $25-29$ & 46 (33.1) & $127(25.5)$ \\
\hline $30-34$ & $28(20.1)$ & $126(25.4)$ \\
\hline 35 and above & $40(28.8)$ & $177(35.6)$ \\
\hline Age in years (Mean \pm SD) & $29.8(5.7)$ & $31.1(5.7)$ \\
\hline \multicolumn{3}{|l|}{ Educational Status } \\
\hline No formal education & 26 (18.6) & 59 (11.9) \\
\hline Up to secondary & $84(60.5)$ & $328(66)$ \\
\hline Higher secondary or above & $29(20.9)$ & $110(22.1)$ \\
\hline \multicolumn{3}{|l|}{ Monthly Income (PKR) } \\
\hline$<8000(<\$ 76.19)$ & $28(20.1)$ & $75(15.1)$ \\
\hline 8001 to 10,000 (\$76.19 - \$95.25) & $16(11.5)$ & 67 (13.5) \\
\hline 10,001 to 12,000 (\$95.25 - \$114.3) & $76(54.7)$ & $274(55.1)$ \\
\hline 12001 to $15,000(\$ 114.3-\$ 142.85)$ & $10(7.2)$ & $32(6.4)$ \\
\hline$>15,000(>\$ 142.85)$ & $9(6.5)$ & 49 (9.9) \\
\hline \multicolumn{3}{|l|}{ Formal Schooling } \\
\hline Yes & $113(81.3)$ & $438(88.1)$ \\
\hline No & $26(18.7)$ & 59 (11.9) \\
\hline \multicolumn{3}{|l|}{ Informal Schooling } \\
\hline Yes & 95 (68.3) & 412 (82.9) \\
\hline No & $44(31.7)$ & $85(17.1)$ \\
\hline \multicolumn{3}{|l|}{ Mother Tongue } \\
\hline Urdu & $126(90.6)$ & 447 (89.9) \\
\hline Gujrati/Mamni & $7(5.1)$ & $31(6.3)$ \\
\hline Sindhi/Punjabi/Pushto/Balochi & $6(4.3)$ & $19(3.8)$ \\
\hline \multicolumn{3}{|l|}{ Type of Marriage } \\
\hline Arranged & 125 (89.9) & $439(88.3)$ \\
\hline Self-choice & $14(10.1)$ & $58(11.7)$ \\
\hline \multicolumn{3}{|l|}{ Any gynaecological and obstetric issues } \\
\hline No issues & $88(63.3)$ & $348(70)$ \\
\hline Miscarriages & $44(31.7)$ & $138(27.8)$ \\
\hline Other reproductive issue & $7(5)$ & $11(2.2)$ \\
\hline \multicolumn{3}{|l|}{ Family Type } \\
\hline Nuclear & $63(45.3)$ & $211(42.5)$ \\
\hline Extended & $76(54.7)$ & $286(57.5)$ \\
\hline \multicolumn{3}{|l|}{ Work Status } \\
\hline Working & $14(10.1)$ & $82(16.5)$ \\
\hline Not working & $125(89.9)$ & $415(83.5)$ \\
\hline \multicolumn{3}{|l|}{ Husband Employed } \\
\hline Not working & $3(2.2)$ & $15(3)$ \\
\hline Working & $136(97.8)$ & $482(97)$ \\
\hline \multicolumn{3}{|l|}{ Own Vehicle } \\
\hline Yes & 58 (41.7) & 268 (53.9) \\
\hline No & $81(58.3)$ & $229(46.1)$ \\
\hline
\end{tabular}

had an arranged marriage. Previous gynaecological and obstetric issues such as (miscarriages, and other reproductive issues) were similar in both the groups. Participants with low resilience were less likely to be working as compared to their counterpart. Husbands of majority of the participants in both the groups were employed. More than half (58.3\%) of the participants with low resilience had no vehicle of their own.

Table 2 presents depression and life satisfaction among the study participants. It was observed that depression was more evident among females with low resilience (43.9\%) versus females with high resilience (26\%). Similarly mean life satisfaction score was lower among females with low resilience 20.95 (SD 4.66) as compared to females with high resilience 23.44 (SD 3.66). 


\subsection{Univariate Analysis}

On univariate analysis as presented in Table 3 we observed that the prevalence of low resilience was $84 \%$ higher among females who were depressed as compared to females who were not depressed. On the other hand with every 1 unit increase in the life satisfaction score the prevalence of low resilience was decreased by $10 \%$. Moreover with every 1 year increase in age the prevalence of low resilience was decreased by $3 \%$

Furthermore the prevalence of low resilience was 1.8 times more among females who had no informal education as compared to those who had acquired informal education. Those participants possessing no vehicles were $47 \%$ more likely to have low resilience as compared to those owning a vehicle. Formal education and years of schooling were also associated with low resilience at a p value of $<0.2$ and were therefore included in the multivariable analysis.

\subsection{Multivariable Analysis}

Table 4(a) presents the first final cox regression model which includes: Depression, age (in years) and informal schooling. It was observed that after adjusting for the other covariates the prevalence of low resilience was 1.76 times more among those who were depressed as compared to those who were not depressed. Moreover with every 1 year increase in age the prevalence of having low resilience was decreased by $4 \%$. The prevalence of low resilience was 1.78 times more among those having no informal schooling versus those with informal schooling with CI (1.23 - 2.54). There was no interaction and confounding found in the model.

Table 4(b) presents the second final cox regression model which includes: Life satisfaction score, age (in years) and informal schooling. It was observed that after adjusting for the other covariates with every one unit increase in the life satisfaction score the prevalence of low resilience was decreased by $9 \%$. Moreover with every 1 year increase in age the prevalence of having low resilience was decreased by $4 \%$. The prevalence of low resilience was 1.74 times more among those having no informal schooling versus those having informal schooling with CI $(1.21$ - 2.5). There was no interaction and confounding found in the model.

Table 2. Depression and life satisfaction among the study participants.

\begin{tabular}{ccc}
\hline Depression and life satisfaction & $\begin{array}{c}\text { Prevalence of low resilience }(\mathbf{n}=\mathbf{1 3 9}) \\
\mathbf{n}(\mathbf{\%})\end{array}$ & $\begin{array}{c}\text { Prevalence of high resilience }(\mathbf{n}=\mathbf{4 9 7}) \\
\mathbf{n}(\%)\end{array}$ \\
\hline Depression & & \\
No & $78(56.1 \%)$ & $368(74 \%)$ \\
Yes & $61(43.9 \%)$ & $129(26 \%)$ \\
Life satisfaction (Mean \pm SD) & $20.95(4.66)$ & $23.44(3.66)$ \\
\hline
\end{tabular}

Table 3. Univariate analysis for factors associated with resilience.

\begin{tabular}{|c|c|c|c|}
\hline Variables & $\begin{array}{l}\text { Prevalence of low resilience } \\
\qquad(\mathbf{n}=139) \\
\mathbf{n}(\%)\end{array}$ & $\begin{array}{l}\text { Prevalence of high resilience } \\
\qquad(\mathrm{n}=497) \\
\mathrm{n}(\%)\end{array}$ & $\begin{array}{l}\text { Crude prevalence ratio } \\
\text { (95\% CI) }\end{array}$ \\
\hline \multicolumn{4}{|l|}{ Depression } \\
\hline No & 78 (56.1\%) & 368 (74\%) & 1 \\
\hline Yes & 61 (43.9\%) & 129 (26\%) & $1.84(1.31-2.56)$ \\
\hline Life satisfaction score & $20.95(4.66)$ & $23.44(3.66)$ & $0.91(0.88-0.94)$ \\
\hline Age (in years) & $29.8(5.7)$ & $31.1(5.7)$ & $0.97(0.94-0.99)$ \\
\hline Years of schooling & $7.4(4.47)$ & $8.2(3.99)$ & $0.97(0.93-1.004)$ \\
\hline $\begin{array}{c}\text { Formal schooling } \\
\text { Yes } \\
\text { No }\end{array}$ & $\begin{array}{l}113(81.3) \\
26(18.7)\end{array}$ & $\begin{array}{l}438(88.1) \\
59(11.9)\end{array}$ & $1.49(0.97-2.28)$ \\
\hline $\begin{array}{c}\text { Informal schooling } \\
\text { Yes } \\
\text { No }\end{array}$ & $\begin{array}{l}95(68.3) \\
44(31.7)\end{array}$ & $\begin{array}{l}412(82.9) \\
85(17.1)\end{array}$ & $1.82(1.27-2.60)$ \\
\hline $\begin{array}{c}\text { Possession of own vehicle } \\
\text { Yes } \\
\text { No }\end{array}$ & $\begin{array}{l}58(41.7) \\
81(58.3)\end{array}$ & $\begin{array}{l}268(53.9) \\
229(46.1)\end{array}$ & $\begin{array}{c}1 \\
1.47(1.05-2.06)\end{array}$ \\
\hline
\end{tabular}


Table 4. Multivariable analysis for factors associated with resilience. (a) Model 1; (b) Model 2.

(a)

\begin{tabular}{|c|c|c|c|c|}
\hline Variables & $\begin{array}{c}\text { Prevalence of } \\
\text { low resilience } \\
(\mathbf{n}=139) \\
n(\%)\end{array}$ & $\begin{array}{c}\text { Prevalence of } \\
\text { high resilience } \\
(\mathrm{n}=497) \\
n(\%)\end{array}$ & $\begin{array}{c}\text { Crude prevalence ratio } \\
\text { (95\% CI) }\end{array}$ & $\begin{array}{c}\text { Adjusted prevalence ratio } \\
\qquad(95 \% \mathrm{CI})\end{array}$ \\
\hline \multicolumn{5}{|l|}{ Depression } \\
\hline No & 78 (56.1\%) & 368 (74\%) & 1 & 1 \\
\hline Yes & $61(43.9 \%)$ & $129(26 \%)$ & $1.84(1.31-2.56)$ & $1.76(1.27-2.51)$ \\
\hline Age (in years) & $29.8(5.7)$ & 31.1 (5.7) & 0.97 (0.94 - 0.99) & $0.96(0.93-0.99)$ \\
\hline \multicolumn{5}{|c|}{ Informal schooling } \\
\hline Yes & $95(68.3)$ & 412 (82.9) & 1 & 1 \\
\hline No & 44 (31.7) & 85 (17.1) & $1.82(1.27-2.60)$ & $1.78(1.23-2.54)$ \\
\hline
\end{tabular}

(b)

\begin{tabular}{ccccc}
\hline Variables & $\begin{array}{c}\text { Prevalence of } \\
\text { low resilience } \\
\mathbf{( n = 1 3 9 )} \\
\mathbf{n ~ ( \% )}\end{array}$ & $\begin{array}{c}\text { Prevalence of } \\
\text { high resilience } \\
\mathbf{( n = 4 9 7 )} \\
\mathbf{n ~ ( \% )}\end{array}$ & $\begin{array}{c}\text { Crude prevalence ratio } \\
\mathbf{( 9 5 \% ~ C I )}\end{array}$ & $\begin{array}{c}\text { Adjusted prevalence ratio } \\
\mathbf{( 9 5 \%} \mathbf{C I})\end{array}$ \\
\hline $\begin{array}{c}\text { Life satisfaction } \\
\text { Age (in years) }\end{array}$ & $20.95(4.66)$ & $23.44(3.66)$ & $0.91(0.88-0.94)$ & $0.91(0.88-0.94)$ \\
$\begin{array}{c}\text { Informal schooling } \\
\text { Yes }\end{array}$ & $29.8(5.7)$ & $31.1(5.7)$ & $0.97(0.94-0.99)$ & $0.96(0.94-0.99)$ \\
No & $95(68.3)$ & $412(82.9)$ & 1 & 1 \\
\hline
\end{tabular}

\section{Discussion}

Our study reports $21.9 \%$ prevalence of low resilience among married women aged 20 to 40 years living in Karachi, Pakistan. However, $78.1 \%$ of the participants were highly resilient. To the best of our knowledge, limited information is available about the prevalence of resilience from Pakistani context among similar population. Although studies have reported the prevalence of depression of 30\% - 60\% among married women in Pakistan but none of them have reported the prevalence of resilience [15] [16]. A possible explanation of our finding could be our country's situation, which has been under a constant threat of violence acts such as: bomb blast, snatching, murders and kidnapping etc. and the intensity of such adversities is increasing day by day. Making the people more or less immune to such challenges. Our study results indicated a higher prevalence of resilience among females that depicts that people are positively responding to such challenges and are therefore exhibiting adaptive and constructive behaviour. Windle also mentioned in one of his study that if one is exposed to constant adversity, it may make him/her more resilient to such challenges [17].

It is observed that among people who are less resilient, when adversity inflicts them it usually results in psychiatric disorders, which includes: post-traumatic stress disorder (PTSD) and major depressive disorder [18]. In our study, we presented two different models firstly to observe the relationship of depression with resilience and secondly to observe the relationship of life satisfaction with resilience. Resilience and depression are inversely proportional which means that individuals who are depressed are more likely to have lower resilience. A study done on African American women has shown that high resiliency score had a statistically significant inverse relationship with depressive symptoms [19]. Our study results also showed that females who were depressed had lower resilience scores which was consistent with the findings from other studies [20]-[23]. The World Health Organization (WHO) has predicted that depression will be the second biggest cause of illness by 2020 [24]. Hence, looking at the increasing trends it is very important to reduce depression by promoting training sessions for enhancement of resilience.

Moreover, our study results also indicated that means life satisfaction scores were lower among females with low resilience. It shows that if ones satisfaction towards life increases, the individual is more likely to be resilient. Studies conducted in communities have also shown that resilience has an association with life satisfaction [25]. Another study highlighted that resilient individuals are those who are socially active and when their life satisfaction scores have been assessed they usually range from mid to high scores. Hence, resilience has a positive effect on an individual's life satisfaction. The WHO emphasizes on prevention of mental health problems by 
promoting positive psychological health [26]. Hence it is important to identify factors that help in promoting satisfaction, happiness and sense of fulfilment towards life, which ultimately increases successful adaptation [27].

In our study, women with low resilience were younger as compared to those with high resilience. Our study results were consistent with the finding from other studies i.e. with increase in age females tend to become more resilient. With time their coping mechanism becomes better and thus they are able to deal with the upcoming challenges of their life in a better way [28].

In addition, our study results also demonstrated that women who had no formal or informal education were more likely to have low resilience. Studies also report that education plays a very crucial role in enhancing resilience among females. This is due to the fact that, once a female steps out of the house to acquire education it not only broadens her horizon towards life but also helps her to get away from the misery of her life [29]. In addition, a study done by Perna's in 2012 also suggested that higher resilience was more evident among those individuals who had acquired higher education [30].

Our study also found that most women with low resilience were non-working as compared to women with high resilience. Literature also suggests that the working status of women also has an effect on the level of their resilience. As Moneith \& Ford-Gilboe in 2002 found that mothers who worked full-time had higher resilience scores as compared to those who worked part-time [31]. Another study done in Pakistan in 2010 also suggests that when females were employed a significant improvement was seen in their self-efficacy [32] hence making them more resilient [33].

Our study also highlighted that majority of the women not possessing a vehicle of their own had low resilience. In our study, this variable was used this as a proxy indicator for socioeconomic status. Hardy in 2004 found that the individuals with higher income had higher resilience when they were inflicted by adversity [34]. Another study by Wagnild also suggests that the financial crisis in an individual's life may lead to discouragement, fear, and a destructive belief and he/she may perceive that his life is useless [26].

\subsection{Strengths}

To the best of our knowledge this study is one of the first ever study conducted on a representative sample of married women from urban squatter settlements of Karachi. Our study results can be extrapolated on urban married females of Pakistan because our population consists of $60 \%$ of married women. Moreover we used a systematic random sampling technique for enrolling our participants which is a robust method of sampling.

Moreover, we used a standardized and rigorous procedure of tool validation before it has been tested on participants. In addition, PI accompanied the data collectors in the field to ensure that the data quality should not be compromised. We have also given mental health supports in the form of referrals and counseling to those who were found depressed.

\subsection{Limitations}

We had several limitations in our study. Firstly reporting bias was evident in our study as there were some sensitive questions to which the females were reluctant to answer, but we tried our level best to give assurance to the participants about the privacy and confidentiality of their information. Secondly we did not inquire about the religious believes, pregnancy status and postpartum which should be taken into account as it can affect the results of resilience and depression respectively [35] [36].

\section{Conclusion}

This study indicates that depression and life satisfaction are potential modifiable risk factors for resilience and hence we can improve resilience through interventions that may help us in reducing depression and increasing life satisfaction [20]. Moreover, our study findings also indicated that higher educational status and socioeconomic status were also associated with resilience. Therefore, it is very essential to empower our females by getting them educated that would stabilize them not only financially but also mentally. Hence this will help them to effectively cope up with the adversities of life.

\section{Recommendations}

Our finding should be utilized to persuade policy makers to extend mental health support for women by encour- 
aging health care professional for a health promotion model then the curative model. Our study findings also recommend that health care professionals should also be educated about these modifiable risk factors such as depression and life satisfaction. This may help us in reducing the economic and psychological burden on the society.

\section{Ethical Approval}

Ethical approval was taken from Aga Khan University Ethical Review Committee (2333-CHS-ERC-12).

\section{Authors Contribution}

SSB: was the principle investigator of this study. This was conducted as part of her MSc Epidemiology \& Biostatistics thesis project. She has contributed throughout the study period. This includes study conception, design, data analysis, interpretation of data and drafted the manuscript.

NZ: supported in additional analysis of study data that is presented in the current paper. She assisted in drafting, revising and finalizing the manuscript.

IA: Senior statistician, he has made major contributions in sample size estimation, data management, analysis and interpretation of data. He has given critical feedback in drafting manuscript.

NA: Clinical psychologist has made extensive contribution during the tools translation and has given considerable input in drafting the manuscript.

RK: Professor, senior researcher and a public health nurse, she has made substantial contribution in the conception of the study and given meaningful feedback on manuscript to be published.

OP: Public Health Physician, researcher and epidemiologist, she has made significant contribution in conception and design of the study. She has given critical feedback on the manuscript.

\section{References}

[1] Wilks, S.E. (2008) Psychometric Evaluation of the Shortened Resilience Scale among Alzheimer's Caregivers. American Journal of Alzheimer's Disease and Other Dementias, 23, 143-149. http://dx.doi.org/10.1177/1533317507313012

[2] Wagnild, G. (2009) The Resilience Scale User's Guide for the US English Version of the Resilience Scale and the 14-Item Resilience Scale (RS-14). The Resilience Center, USA.

[3] Becker, G. and Newsom, E. (2005) Resilience in the Face of Serious Illness among Chronically Ill African Americans in Later Life. The Journals of Gerontology Series B: Psychological Sciences and Social Sciences, 60, S214-S223. http://dx.doi.org/10.1093/geronb/60.4.s214

[4] Resnick, B.A. and Inguito, P.L. (2011) The Resilience Scale: Psychometric Properties and Clinical Applicability in Older Adults. Archives of Psychiatric Nursing, 25, 11-20. http://dx.doi.org/10.1016/j.apnu.2010.05.001

[5] Noya, A. and Clarence, E. (2009) Community Capacity Building: Fostering Economic and Social Resilience. Organisation for Economic Cooperation and Development, 26-27.

[6] Sanders, A.E., Lim, S. and Sohn, W. (2008) Resilience to Urban Poverty: Theoretical and Empirical Considerations for Population Health. American Journal of Public Health, 98, 1101-1106. http://dx.doi.org/10.2105/AJPH.2007.119495

[7] Abrams, M.S. (2001) Resilience in Ambiguous Loss. American Journal of Psychotherapy, 55, 283.

[8] Hjemdal, O., Vogel, P.A., Solem, S., Hagen, K. and Stiles, T.C. (2010) The Relationship between Resilience and Levels of Anxiety, Depression, and Obsessive Compulsive Symptoms in Adolescents. Clinical Psychology \& Psychotherapy, 18, 314-321. http://dx.doi.org/10.1002/cpp.719

[9] Resnick, B., Galik, E., Dorsey, S., Scheve, A. and Gutkin, S. (2011) Reliability and Validity Testing of the Physical Resilience Measure. Gerontologist, 51, 643-652. http://dx.doi.org/10.1093/geront/gnr016

[10] Ryan, L. and Caltabiano, M.L. (2009) Development of a New Resilience Scale: The Resilience in Midlife Scale (RIM Scale). Asian Social Science, 5, 39. http://dx.doi.org/10.5539/ass.v5n11p39

[11] Ali, F.A. and Zuberi, R.W. (2012) Association of Sociodemographic Factors with Depression in Women of Reproductive Age. Asia-Pacific Journal of Public Health, 24, 161-172. http://dx.doi.org/10.1177/1010539510364668

[12] Diego-Adellino, J.D., Portella, M.J., Puigdemont, D., Perez-Egea, R., Alvarez, E. and Perez, V. (2010) A Short Duration of Untreated Illness (DUI) Improves Response Outcomes in First-Depressive Episodes. Journal of Affective Disorders, 120, 221-225. http://dx.doi.org/10.1016/j.jad.2009.03.012

[13] Bhamani, S.S., Pasha, O., Karmaliani, R., Asad, N. and Azam, I. Validation of the Urdu Version of the Wagnild and Young's Long and Short Resilience Scales among 20-40 Years Old, Married Women Living in Urban Squatter Settle- 
ments of Karachi, Pakistan. Journal of Nursing Measurement, In Press.

[14] Wagnild, G.M. and Young, H.M. (1993) Development and Psychometric Evaluation of the Resilience Scale. Journal of Nursing Measurement, 1, 165-178.

[15] Zahidie, A. and Jamali, T. (2013) An Overview of the Predictors of Depression among Adult Pakistani Women. Journal of the College of Physicians and Surgeons Pakistan, 23, 574-580.

[16] Zainab, S., Fatmi, Z. and Kazi, A. (2012) Risk Factors for Depression among Married Women Belonging to Higher and Lower Socioeconomic Status in Karachi, Pakistan. Journal of the Pakistan Medical Association, 62, 249-253.

[17] Windle, G. (2011) What Is Resilience? A Review and Concept Analysis. Reviews in Clinical Gerontology, 21, $152-169$. http://dx.doi.org/10.1017/S0959259810000420

[18] Wagnild, G.M. and Collins, J.A. (2009) Assessing Resilience. Journal of Psychosocial Nursing and Mental Health Services, 47, 28-33. http://dx.doi.org/10.3928/02793695-20091103-01

[19] Holden, K.B., Bradford, L.D., Hall, S.P. and Belton, A.S. (2013) Prevalence and Correlates of Depressive Symptoms and Resiliency among African American Women in a Community-Based Primary Health Care Centre. Journal of Health Care for the Poor and Underserved, 24, 79-93.

[20] Nishi, D., Uehara, R., Kondo, M. and Matsuoka, Y. (2010) Reliability and Validity of the Japanese Version of the Resilience Scale and Its Short Version. BMC Research Notes, 3, 310. http://dx.doi.org/10.1186/1756-0500-3-310

[21] Abiola, T. and Udofia, O. (2011) Psychometric Assessment of the Wagnild and Young's Resilience Scale in Kano, Nigeria. BMC Research Notes, 4, 509. http://dx.doi.org/10.1186/1756-0500-4-509

[22] Heilemann, M.V., Lee, K. and Kury, F.S. (2003) Psychometric Properties of the Spanish Version of the Resilience Scale. Journal of Nursing Measurement, 11, 61-72. http://dx.doi.org/10.1891/jnum.11.1.61.52067

[23] Wagnild, G.M. and Young, H.M. (1993) Development and Psychometric Evaluation of the Resilience Scale. Journal of Nursing Measurement, 1, 165-178.

[24] Murray, C.J.L. and Lopez, A.D. (1996) Evidence-Based Health Policy-Lessons from the Global Burden of Disease Study. Science, 274, 740-743. http://dx.doi.org/10.1126/science.274.5288.740

[25] Beutel, M.E., Glaesmer, H., Wiltink, J., Marian, H. and Brahler, E. (2010) Life Satisfaction, Anxiety, Depression and Resilience across the Life Span of Men. The Aging Male, 13, 32-39. http://dx.doi.org/10.3109/13685530903296698

[26] Wagnild, G. (2009) A Review of the Resilience Scale. Journal of Nursing Measurement, 17, 105-113. http://dx.doi.org/10.1891/1061-3749.17.2.105

[27] World Health Organisation (2013) Mental Health Action Plan 2013-2020. http://www.who.int/mental health/publications/action plan/en/

[28] Nygren, B., Randstrom, K.B., Lejonklou, A.K. and Lundman, B. (2004) Reliability and Validity of a Swedish Language Version of the Resilience Scale. Journal of Nursing Measurement, 12, 169-178. http://dx.doi.org/10.1891/jnum.12.3.169

[29] Valentine, L. and Feinauer, L.L. (1993) Resilience Factors Associated with Female Survivors of Childhood Sexual Abuse. American Journal of Family Therapy, 21, 216-224. http://dx.doi.org/10.1080/01926189308250920

[30] Perna, L., Mielck, A., Lacruz, M.E., Emeny, R.T., Holle, R., Breitfelder, A. and Ladwig, K.H. (2012) Socioeconomic Position, Resilience, and Health Behaviour among Elderly People. International Journal of Public Health, 57, $341-349$. http://dx.doi.org/10.1007/s00038-011-0294-0

[31] Monteith, B. and Ford-Gilboe, M. (2002) The Relationships among motherâ€ ${ }^{\mathrm{TM}_{\mathrm{S}}}$ Resilience, Family Health Work, and motherâ€ $€^{\mathrm{TM}_{\mathrm{S}}}$ Health-Promoting Lifestyle Practices in Families with Preschool Children. Journal of Family Nursing, 8, 383-407. http://dx.doi.org/10.1177/107484002237514

[32] Hirani, S.S., Karmaliani, R., McFarlane, J., Asad, N., Madhani, F. and Shehzad, S. (2010) Testing a Community Derived Intervention to Promote Women's Health: Preliminary Results of a 3-Arm Randomized Controlled Trial in Karachi, Pakistan. Southern Online Journal of Nursing Research, 10, 10 p.

[33] Damasio, B.F., Borsa, J.C. and da Silva, J.P. (2011) 14-Item Resilience Scale (RS-14): Psychometric Properties of the Brazilian Version. Journal of Nursing Measurement, 19, 131-145. http://dx.doi.org/10.1891/1061-3749.19.3.131

[34] Hardy, S.E., Concato, J. and Gill, T.M. (2004) Resilience of Community-Dwelling Older Persons. Journal of the American Geriatrics Society, 52, 257-262. http://dx.doi.org/10.1111/j.1532-5415.2004.52065.x

[35] Brewer-Smyth, K. and Koenig, H.G. (2014) Could Spirituality and Religion Promote Stress Resilience in Survivors of Childhood Trauma? Issues in Mental Health Nursing, 35, 251-256. http://dx.doi.org/10.3109/01612840.2013.873101

[36] Ali, N.S., Azam, I.S., Ali, B.S., Tabbusum, G. and Moin, S.S. (2012) Frequency and Associated Factors for Anxiety and Depression in Pregnant Women: A Hospital-Based Cross-Sectional Study. The Scientific World Journal, 2012, Article ID: 653098. 